\title{
Estimation of deep fault geometry of the Nagamachi-Rifu fault from seismic array observations
}

\author{
Ayako Nakamura, Youichi Asano, and Akira Hasegawa \\ Research Center for Prediction of Earthquakes and Volcanic Eruptions, Graduate School of Science, Tohoku University, Sendai 980-8578, Japan
}

(Received December 28, 2001; Revised September 26, 2002; Accepted September 27, 2002)

\begin{abstract}
An extensive seismic experiment was carried out in June 2001 around the Nagamachi-Rifu fault, northeastern Japan. We deployed seismic arrays on the hanging wall of the reverse fault, and observed seismic waves caused by chemical explosions and vibrators. Several later arrivals from reflectors, whose depths are about 9 to $21 \mathrm{~km}$, are detected in the observed shot gathers. Some of them probably correspond to $S$-wave reflectors and scatterers previously estimated from the data of natural earthquakes. A clear reflector was found in and below the seismogenic layer at 4 to 4.5 -s two-way traveltime (TWTT). It is located at the shallower and deeper extensions of the fault plane of M5.0 earthquake that occurred in 1998. Its extension to the surface seems to connect with the surface trace of the Nagamachi-Rifu fault. These suggest that the Nagamachi-Rifu fault has a low dip-angle in the mid-crust as a detachment fault, if the reflector shows the fault structures.
\end{abstract}

\section{Introduction}

Northeastern Japan is a typical subduction zone, where the Pacific plate subducts beneath the land area at a rate of $\sim 10 \mathrm{~cm} /$ year. Many shallow earthquakes occur within the overriding continental plate. They concentrate to the areas along the volcanic front and along active faults (Hasegawa $e t$ al., 2000). Nagamachi-Rifu fault is one of such active faults and is going through Sendai City, northeastern Japan (Fig. 1). It is a $17-\mathrm{km}$-long reverse fault striking in the northeastsouthwest direction and dipping to the northwest. Its past activity was investigated based on topographic and geologic surveys. Active Fault Research Group (1991) estimated that the average fault slip rate is about $0.7 \mathrm{~m} / 1000$ years. Sendai City has a population of one million and if the NagamachiRifu fault slips and generates a large earthquake, it will cause serious damages to the urban area of the city.

An earthquake with M5.0 occurred at $\sim 12 \mathrm{~km}$ depth near the Nagamachi-Rifu fault on September 15. It caused a slight damage to some areas of the city. Umino et al. (2002a) suggested that this earthquake slipped at the deepest portion of the Nagamachi-Rifu fault based on the geometrical relationship between the fault plane of the M5.0 event and the surface trace of the Nagamachi-Rifu fault. Energetic surveys have been made to investigate the deep structure of inland active faults, particularly in the San Andreas Fault Zone. Zhu (2000) and other groups (Feng and McEvilly, 1983; McBride and Brown, 1986; Eberhart-Phillips et al., 1990; Holbrook et al., 1996; Henstock et al., 1997; Parsons, 1998) suggested that the San Andreas Fault extended through the entire crust. On the other hand, Furlong et al. (1989) and Brocher et al. (1994) suggested that there exists a horizontal detachment

Copy right(C) The Society of Geomagnetism and Earth, Planetary and Space Sciences (SGEPSS); The Seismological Society of Japan; The Volcanological Society of Japan; The Geodetic Society of Japan; The Japanese Society for Planetary Sciences. in the mid-crust and the fault was decoupled from the mantle lithosphere. Information on the deep structure of the Nagamachi-Rifu fault is also important for understanding the generation process of inland earthquakes and for evaluating the seismic potential in this city.

To test the hypothesis that the Nagamachi-Rifu fault extends to the lower-crust, an active-source seismic experiment was carried out in June 2001 (Hasegawa et al., 2001). In this paper we present seismic sections observed in the northwestern side of the surface trace of the Nagamachi-Rifu fault. Based on these seismic sections, we investigate whether or not there exists the deeper extension of the Nagamachi-Rifu fault, which is a "non-interplate" active fault.

\section{Seismic Experiment}

Seismic data analyzed in this study were acquired in the seismic experiment reported by the Research Group for Deep Structure of Nagamachi-Rifu Fault (2002). This experiment was an extensive program and included active and passive recording of chemical explosions, truck mounted vibrators, and natural earthquakes. Two seismic reflection profiles formed the backbone of the experiment (lines A and B in Fig. 1). One of the profiles, the 20-km-long NW-SE profile, was perpendicular to the Nagamachi-Rifu fault, and the other, the $15-\mathrm{km}$-long profile, was parallel to the fault. 14 chemical explosions ( 80 to $120 \mathrm{~kg}$ ) were detonated on the hanging wall of the Nagamachi-Rifu fault and one $(100 \mathrm{~kg})$ on the footwall of the fault (stars in Fig. 1). Details of the experiment and data acquisition are given by Hasegawa et al. (2001), Ikawa et al. (2001), Research Group for Deep Structure of Nagamachi-Rifu Fault (2002) and Hasegawa et al. (2001).

Each research group set up their own observation stations during the experiment. In the present study, we used the data acquired by Research Group for Deep Structure of 


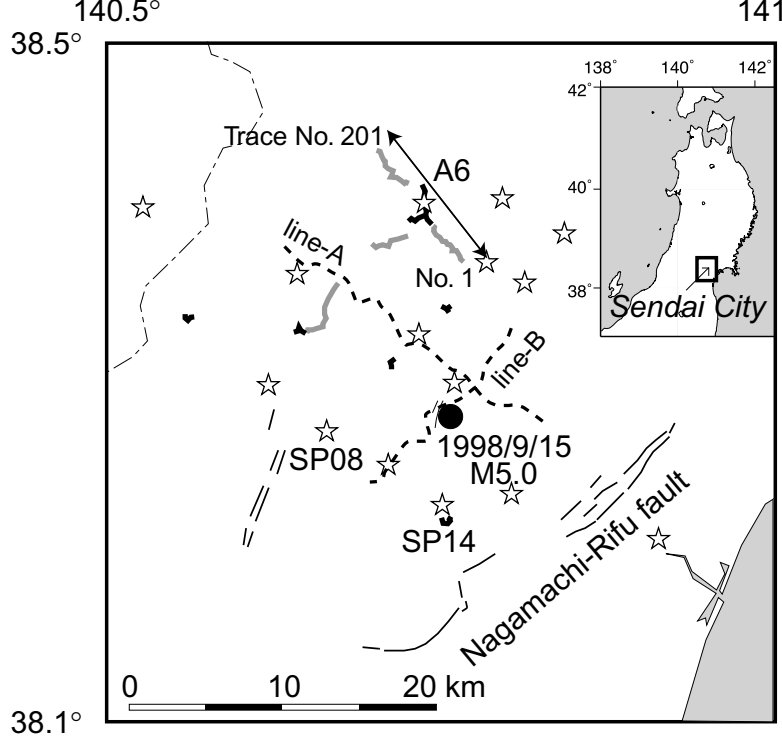

Fig. 1. Locations of shot points (stars), receiver arrays (black and gray lines), and reflection profiles (dashed lines). Receiver array A6 and sho points SP08 and SP14 were used in this study. Active fault traces (Active Fault Research Group, 1991) and the epicenter location of 1998 M5.0 earthquake are also shown by thin lines and a solid circle, respectively. Inserted map shows the location of Sendai City and study area.

Nagamachi-Rifu Fault and Joint group comprised of Tohoku University, Ehime University and Yamagata University. The former group set up two off-line arrays, each of which is $\sim 10$-km-long and parallel to the main profile. The array was called A6 and is shown in Fig. 1. Details are given in a report written by Research Group for Deep Structure of Nagamachi-Rifu Fault (2002). The latter group deployed small aperture 5 seismic arrays in the study area (black lines in Fig. 1). Three-component seismometers with natural frequencies of 2 or $4.5 \mathrm{~Hz}$ were deployed with a 50-m separation in each array.

\section{Crustal Reflectivity around the Nagamachi-Rifu Fault}

Figures 2(a) and 2(b) show shot gathers from shots SP08 and SP14 recorded at the array A6, respectively. When the source is close to the stations, reflected waves were contaminated by large-amplitude surface waves. Therefore we used the shot gathers whose epicentral distances are larger than $10 \mathrm{~km}$ in the following analysis. Waveform data were processed with a band-pass filter $(6-24 \mathrm{~Hz})$ and a $2.0-\mathrm{s}$ trailing automatic gain control. There exist several coherent reflection events at about 5 to 7 -s from the origin-times. Their apparent velocities are equal to or slightly higher than those of direct $P$-waves. Figures 3(a) and 3(b) are the shot gathers after normal-moveout (NMO) correction. One-dimensional velocity structure assumed in NMO correction is shown in Fig. 4(b). Cut off above about 2-s in two-way traveltime in Figs. 3(a) and 3(b) is due to normal-moveout stretching.

We picked up relatively remarkable two onsets of the reflection events taking into consideration of their amplitudes and spatial continuity, although it is not easy to detect the onsets of the cloud of reflection arrivals. They are shown by solid circles and solid triangles in Figs. 2(a), 2(b), 3(a), and 3(b). One of them, denoted by solid circles in Figs. 2(a), 2(b), 3(a), and 3(b), is located at depth of 16 to $17 \mathrm{~km}$. Umino et al. (2002b) found several $S$-wave reflectors at 15 to $20 \mathrm{~km}$ depths directly below and west of the fault plane of the M5.0 earthquake (Fig. 4). Asano et al. (2000) found $P$-wave scatterers and $S$-wave scatterers nearly at the same locations as those of $S$-wave reflectors. The location of the $P$-wave reflector denoted by solid circles agrees with these $S$-wave reflectors or scatterers. It seems reasonable to suppose that directly below the Nagamachi-Rifu fault there exist reflectors/scatterers that reflect/scatter $P$ - and $S$-waves.

Another remarkable event denoted by solid triangles in Figs. 2(a), 2(b), 3(a), and 3(b) is observed at 5 to 6-s from the origin-times (Figs. 2(a) and 2(b)) and 4 to 5-s TWTT (Figs. 3(a) and 3(b)). It seems that the apparent velocity of the event shown in Fig. 2(b) is almost equal to that of the direct $P$-wave arrival. However, we infer that the event is not a multiple but a reflection event caused by a dipping reflector referring to other record sections of the SP14 (Research Group for Deep Structure of Nagamachi-Rifu Fault, 2002). It seems to be located nearly at the fault plane of the M5.0 event and at deeper or shallower extension of it. To check this, we estimated by trial and error the three-dimensional geometry of the reflection surface with curvature which explains the observed traveltimes of the reflected waves. 3D raytracing technique (Červený et al., 1988) was used to calculate the synthetic traveltimes. We assumed that the strike of the reflection plane is parallel to the surface trace of the Nagamachi-Rifu fault. Traveltimes of the reflected waves were calculated using the same velocity structure model as that assumed in the NMO correction (Fig. 4(b)). It is based on the velocity model used in the hypocenter determinations in the seismic network of Tohoku University (Hasegawa et al., 1978). Estimated surface of the reflector is shown by contour lines in Fig. 4(a). Reflection points are shown on a map view and a vertical cross section in Figs. 4(a) and 5, respectively. Solid bold lines denote a spatial extent of the estimated reflection points from a shot gather record, whose shot-number is also indicated. Synthetic traveltimes of the reflected waves are shown by contour lines in Figs. 6(a) and 6(b). Calculated traveltimes at both ends of the array are shown by solid circles in Figs. 2(a), 2(b), 3(a), and 3(b). Traveltime residuals of the reflected waves at each station are not more than 0.2-s for the shots SP08 and SP14. Therefore the estimated reflector surface shown in Fig. 4(a) well explains the observed traveltimes of the reflected waves. The estimated reflector is located along the deeper and shallower extensions of the fault plane of the M5.0 earthquake as shown in Fig. 5. It also seems that the extension of the reflector connects with the surface trace of the NagamachiRifu fault (Fig. 5). Figure 5 also shows the migrated depth section along the reflection line A obtained by the seismic reflection experiment (Ikawa et al., 2001). We can see several reflection events, which are located close to and are almost parallel to the reflector presently estimated (SP08 and SP14) and the fault plane of the M5.0 event. This shows that the same reflector as that presently estimated is also detected by the reflection profiling, although it is merely one of those reflection events. Simple shot-gather records (Figs. 3(a) and 3(b)), however, suggest that the reflector surface, form- 
(a) SP08

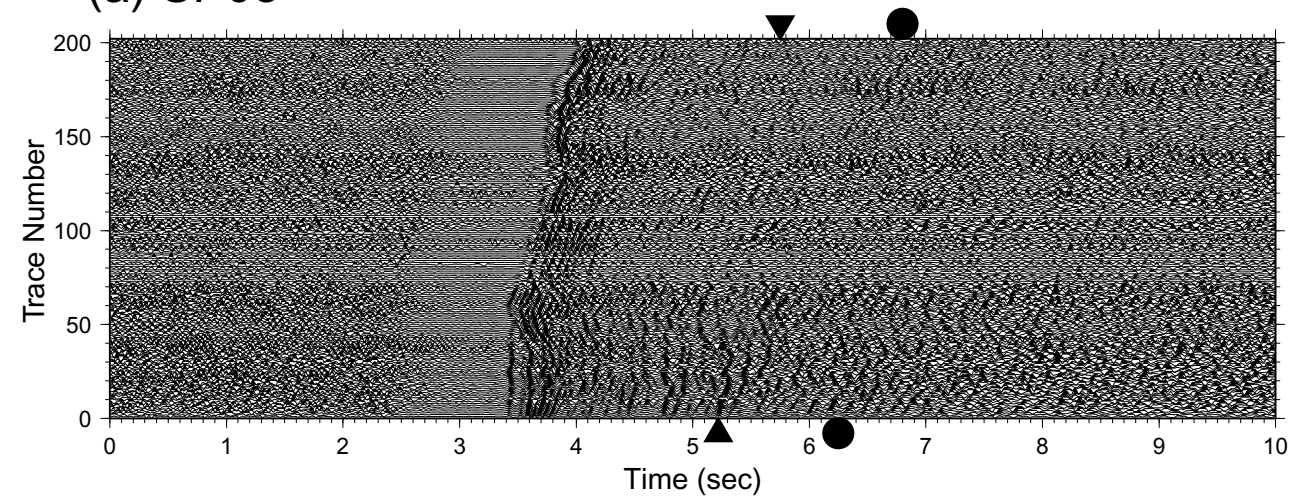

(b) SP14

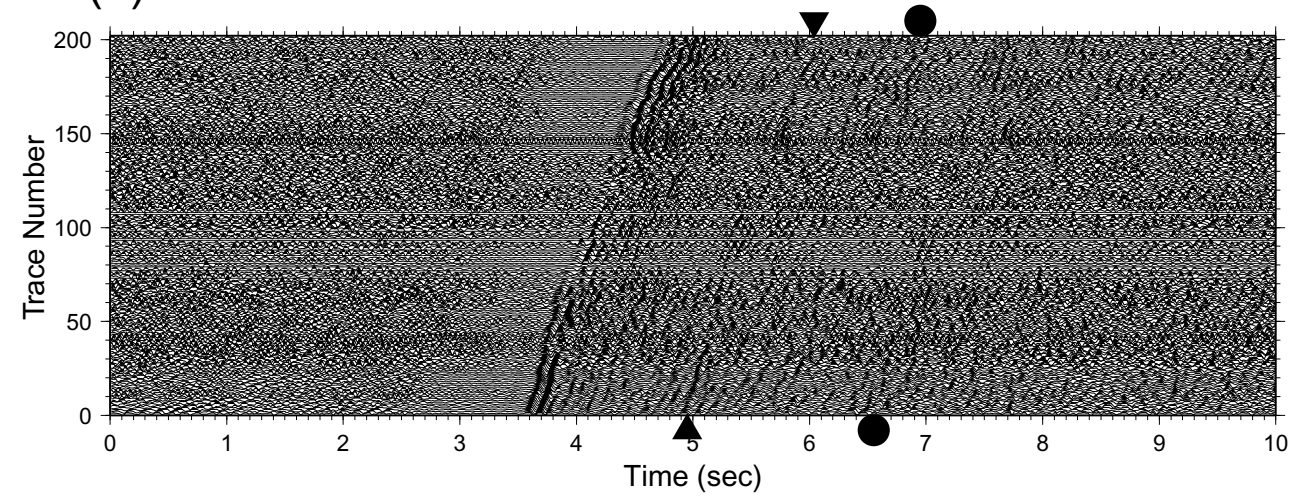

Fig. 2. Shot gather records of (a) SP08 and (b) SP14 obtained at array A6. Observed waveform data are processed with a band-pass filter (6-24 Hz) and a 2.0-s trailing automatic gain control. Solid triangles and solid circles show arrivals of remarkable reflection events.

(a) SP08

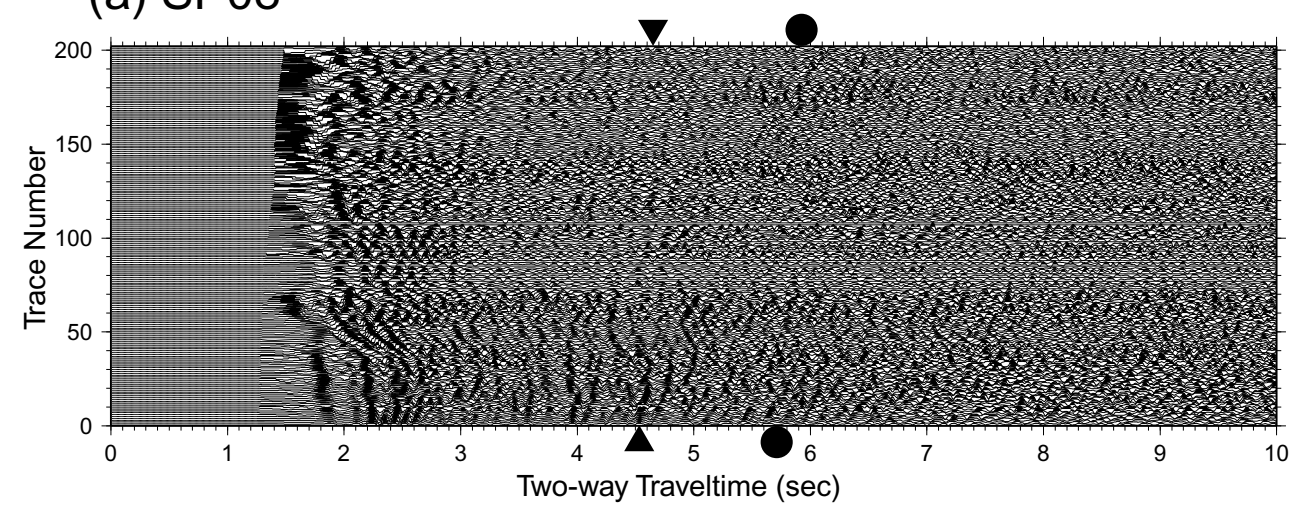

(b) SP14

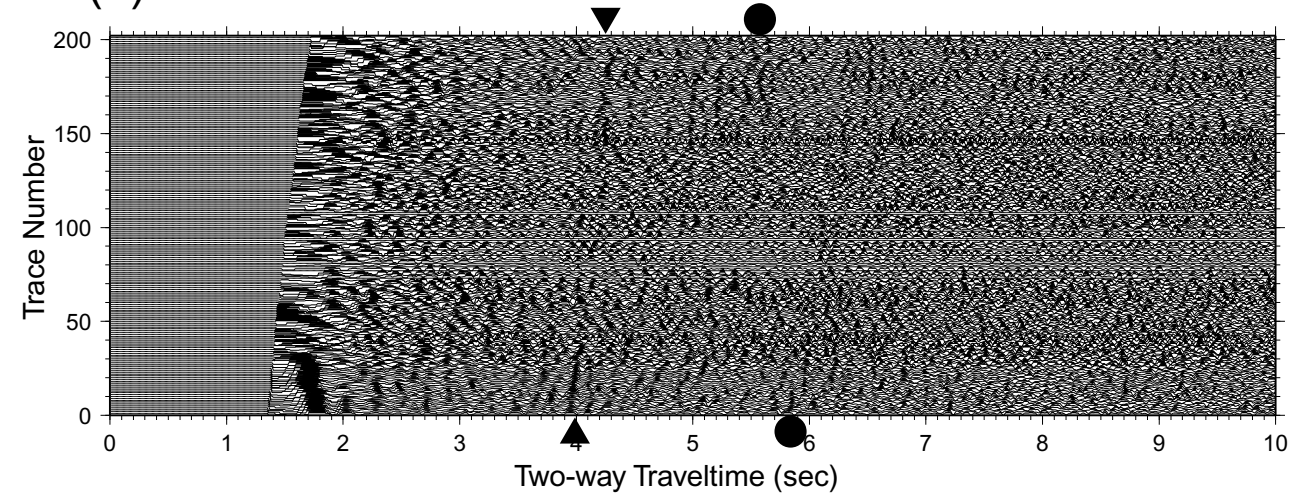

Fig. 3. Shot gather records of (a) SP08 and (b) SP14 after normal-moveout (NMO) correction. NMO correction is applied to the shot gathers in Figs. 2(a) and 2(b) assuming a one-dimensional velocity structure model (Fig. 4(b)). Solid triangles and solid circles show arrivals of remarkable reflection events. 
(a)

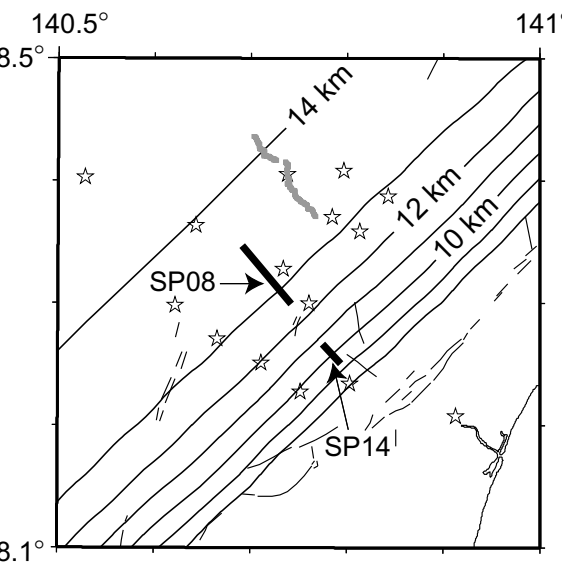

(b)

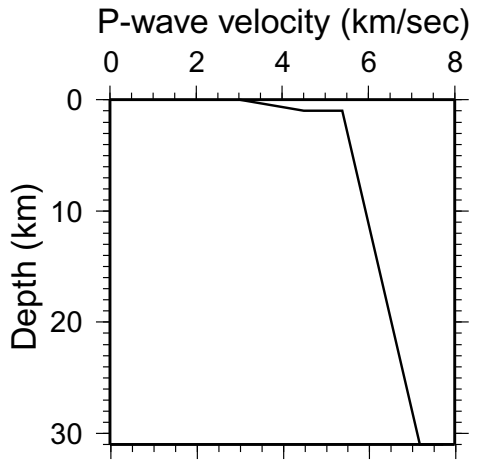

Fig. 4. (a) Estimated reflector surface and reflection points. The depth of the reflector surface is shown by contours. Reflection points to array A6 from shots SP08 and SP14 is shown by bold lines. (b) One-dimensional $P$-wave velocity structure model used to calculate the synthetic traveltimes of reflected waves and to apply NMO correction to the shot gather records.

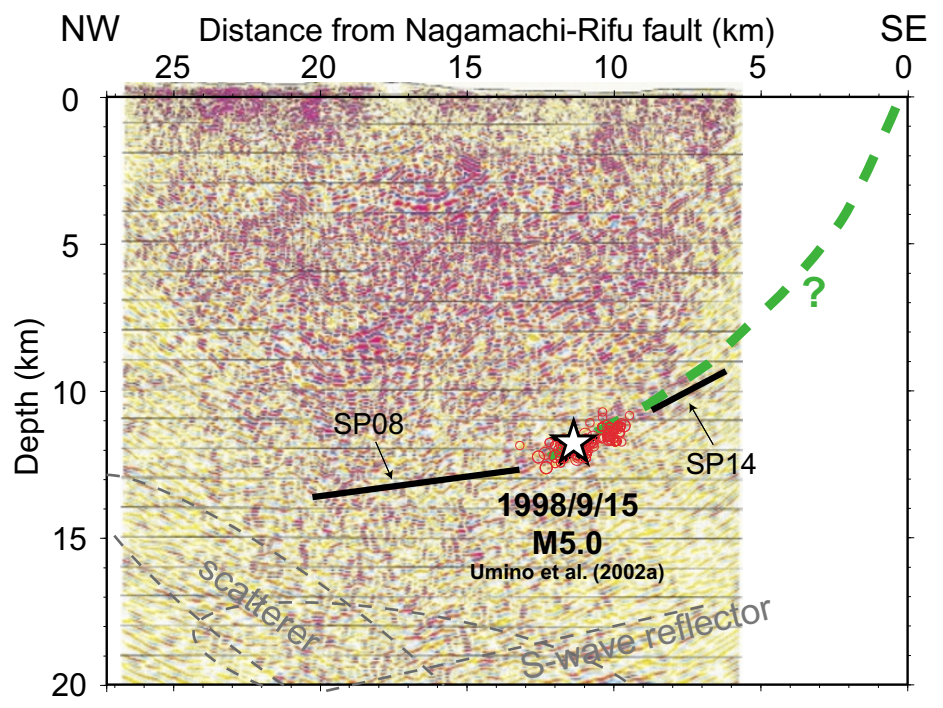

Fig. 5. Migrated depth section along reflection line A (Ikawa et al., 2001). Horizontal-axis is the distance from the Nagamachi-Rifu fault. Bold black lines show the locations of reflection points presently estimated from the shot gather records of SP08 and SP14. Hypocenter of the M5.0 earthquake (star) and its aftershocks (red circles) are also shown (Umino et al., 2002a). Gray broken lines show locations of scatterers and an S-wave reflector estimated by Asano et al. (2000) and Umino et al. (2002b), respectively.

(a)



(b)

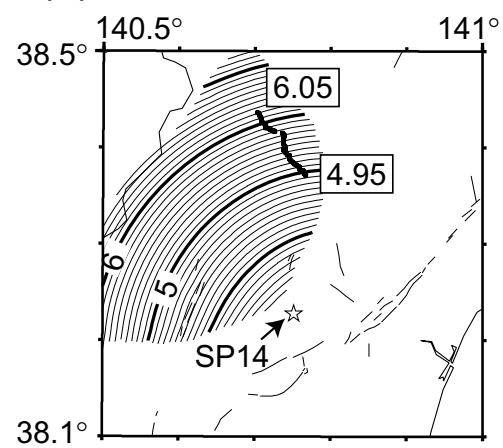

Fig. 6. (a) Calculated traveltimes of reflected waves from (a) SP08 and (b) SP14. Traveltimes are shown by contours. The observed traveltimes at both end of the array A6 are also shown in each figure. 
ing the deeper and shallower extensions of the fault plane of the M5.0 event, is the most remarkable one among the several reflection events imaged by the reflection profiling.

The present results show that the Nagamachi-Rifu fault seems to flatten and merge to a low-angle detachment fault in the mid-crust, if the estimated reflection plane corresponds to the fault structures. Aseismic deformation in the lower crust might have concentrated in this sub-horizontal layer and strain accumulation at the deepest portion of the Nagamachi-Rifu fault might have caused M5.0 earthquake. Actually, Nishimura et al. (2001) suggested that there exists quasi-static sliding on deep extension of the seismogenic Nagamachi-Rifu fault from GPS observations.

Yoshida (2001) investigated the spatial distribution of calderas in northeastern Japan. In the present study area, there exist calderas west of the M5.0 earthquake. He suggested that plutons exist at middle crustal depth under calderas. In our experiment, resolution was not clear enough at $10 \mathrm{~km}$ or shallower depths to detect these plutons.

\section{Conclusions}

We observed seismic signals from both chemical explosions and vibrators by seismic arrays deployed on the hanging wall of the Nagamachi-Rifu fault. We found reflection events from 9 to $21 \mathrm{~km}$ depths around the fault plane of the 1998 M5.0 earthquake. Locations of some reflectors correspond to the $S$-wave reflectors and scatterers previously detected by using data of natural earthquakes. A remarkable reflector in the mid-crust was found along the shallower and deeper extensions of the fault plane of the M5.0 event. The shallower extension of the reflector seems to connect with the surface trace of the Nagamachi-Rifu fault. These observations suggest that the Nagamachi-Rifu fault flattens and merges to low-angle detachment in the mid crust.

Acknowledgments. We thank T. Yokokura and an anonymous reviewer for their comments which improved the present manuscript. We are grateful to all the members of the Research Group for Deep Structure of Nagamachi-Rifu fault and all the members who participated in the field works and data processing. All figures were created using the Genetic Mapping Tool (Wessel and Smith, 1991).

\section{References}

Active Fault Research Group, Active Faults in Japan: sheet maps and inventories (Revised edition), 437 pp., University of Tokyo Press, Tokyo, 1991 (in Japanese).

Asano, Y., N. Umino, S. Hori, and A. Hasegawa, Bright reflective layer beneath the fault of an M5.0 earthquake that occurred in Sendai, northeastern Japan, EOS Trans. AGU, 81, Fall Meet. Suppl., F872, 2000.

Brocher, T. M., J. McCarthy, P. E. Hart, W. S. Holbrook, K. P. Furlong, T. V. McEvilly, J. A. Hole, and S. L. Klemperer, Seismic evidence for a lowercrustal detachment beneath San Francisco bay, California, Science, 265, 1436-1439, 1994.

Červený, V., L. Klimeš, and I. Pšenčík, Complete seismic-ray tracing in three-dimensional structures, in Seismological Algorithms, edited by D. J. Doornbos, 469 pp., Academic Press, New York, 1988.
Eberhart-Phillips, D., M. Lisowski, and M. D. Zoback, Crustal strain near the big bend of the San Andreas fault: Analysis of the Los PadresTehachapi trilateration networks, California, J. Geophys. Res., 95, 11391153, 1990.

Feng, R. and T. V. McEvilly, Interpretation of seismic reflection profiling data for the structure of the San Andreas fault zone, Bull. Seism. Soc. Am., 73, 1701-1720, 1983.

Furlong, K. P., W. D. Hugo, and G. Zandt, Geometry and evolution of the San Andreas fault zone in northern California, J. Geophys. Res., 94, 3100-3110, 1989.

Hasegawa, A., N. Umino, and A. Takagi, Double-planed structure of the deep seismiczone in the northeastern Japan arc, Tectonophys., 47, 43-58, 1978.

Hasegawa, A., A. Yamamoto, N. Umino, S. Miura, S. Horiuchi, D. Zhao, and $\mathrm{H}$. Sato, Seismic activity and deformation process of the overriding plate in the northeastern Japan subduction zone, Tectonophys., 319, 225239, 2000.

Hasegawa, A., H. Ito, T. Iwasaki, and T. Ikawa, Deep structure of Nagamachi-Rifu fault as inferred from seismic expeditions, the Proceedings of the International Symposium on Slip and Flow Processes in and Below the Seismogenic Region, 67-72, 2001.

Henstock, T. J., A. Levander, and J. A. Hole, Deformation in the lower crust of the San Andreas fault system in northern California, Science, 278, 650-653, 1997.

Holbrook, W. S., T. M. Brocher, U. S. ten Brink, and J. H. Hole, Crustal structure of a transform plate boundary: San Francisco Bay and the Central California continental, J. Geophys. Res., 101, 22311-22334, 1996.

Ikawa, T., T. Kawanaka, S. Kawasaki, A. Hasegawa, N. Umino, A. Nakamura, H. Ito, T. Iwasaki, and H. Sato, Seismic reflection survey of the deep structure of Nagamachi-Rifu fault, northeastern Japan, Proceedings of international symposium on slip and flow process in and below the seismogenic region, 44, 2001.

McBride, J. H. and L. D. Brown, Reanalysis of the COCORP deep seismic reflection profile across the San Andreas fault, Parkfield, California, Bull. Seism. Soc. Am., 76, 1668-1686, 1986.

Nishimura, T., T. Sagiya, T. Tada, and S. Miura, High strain rate west of the Nagamachi-Rifu fault, northeastern Japan, observed by a dense GPS array, Proceedings of international symposium on slip and flow process in and below the seismogenic region, 55, 2001.

Parsons, T., Seismic-reflection evidence that the Hayward fault extends into the lower crust of the San Francisco bay area, California, Bull. Seism. Soc. Am., 88, 1212-1223, 1998.

Research Group for Deep Structure of Nagamachi-Rifu Fault, Seismic reflection survey in Nagamachi-Rifu fault, Sendai, Japan, Tohoku Geophys. J., 2002 (submitted).

Umino, N., T. Okada, and A. Hasegawa, Foreshock and aftershock source sequence of 1998 M5.0 Sendai, northeastern Japan, earthquake and its implications for earthquake nucleation, Bull. Seism. Soc. Am., 2002a (in press).

Umino, N., H. Ujikawa, S. Hori, and A. Hasegawa, Distinct S-wave reflectors (bright spots) detected beneath the Nagamachi-Rifu fault, NE Japan, Earth Planets Space, 54, this issue, 1021-1026, 2002 b.

Wessel, P. and W. H. F. Smith, Free software helps map and display data, EOS Trans. $A G U, \mathbf{7 2}, 411,445-456,1991$.

Yoshida, T., The evolution of arc magmatism in the NE Honshu arc, Japan, Tohoku Geophys. J., 36, 131-149, 2001.

Zhu, L., Crustal structure across the San Andreas Fault, southern California from teleseismic converted waves, Earth Planet. Sci. Lett., 179, 183-190, 2000 .

A. Nakamura (e-mail: nakamura@aob.geophys.tohoku.ac.jp), Y. Asano (e-mail: asano@aob.geophys.tohoku.ac.jp), and A. Hasegawa (e-mail: hasegawa@aob.geophys.tohoku.ac.jp) 